\section{Deep enteroscopy diagnosis of obscure overt gas- trointestinal bleeding due to intravascular endo- thelial hyperplasia missed by capsule endoscopy}

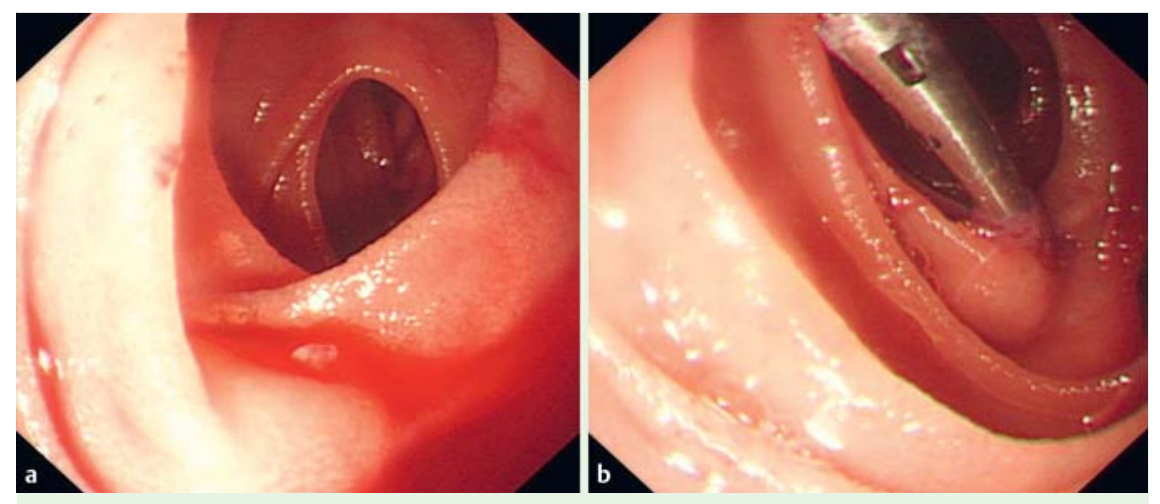

Fig. 1 Single-balloon enteroscopy images showing a submucosal prominent lesion (approximately $0.5 \times 0.5 \mathrm{~cm}$ ) that was streaming with blood, with white thrombus attached to its surface: a before the titanium clip was applied; $\mathbf{b}$ after the titanium clip was applied.

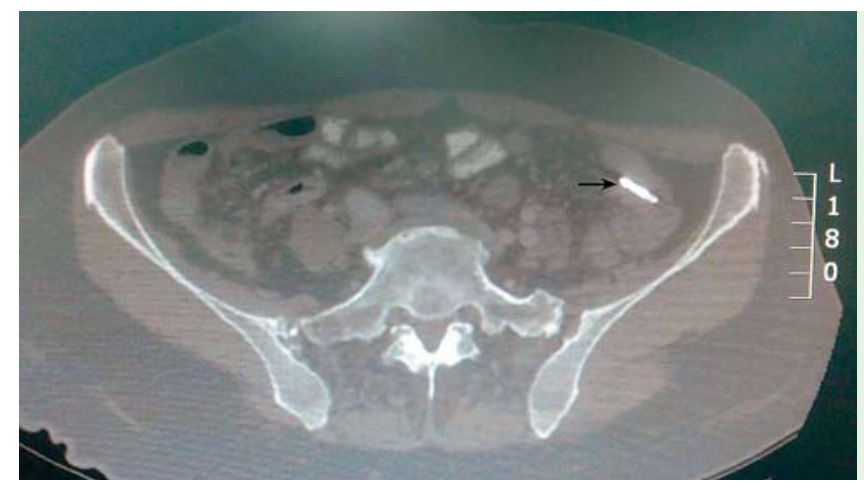

Fig. 2 Abdominal computed tomography (CT) scan showing the location of the titanium clip (arrow) before the operation.

A 56-year-old woman was referred to our hospital with a 3-day history of melena. She reported a 3-year history of dull pain in the left iliac region and intermittent melena. She had no history of drug use, fever, nausea, vomiting, or weight loss. Her vital signs were stable. She appeared pale and was tender in the left iliac region, but without guarding or rebound tenderness. Rectal examination confirmed melena. Laboratory investigation showed a red cell count of $3.16 \times 10^{12} / \mathrm{L}$ and hemoglobin of $85.0 \mathrm{~g} / \mathrm{L}$. Other laboratory values were normal.

The results of esophagogastroduodenoscopy (EGD) and colonoscopy were negative. Capsule endoscopy also failed to identify any blood in the gastrointestinal
(GI) tract. Given the possibilities of a blind spot in vision of the capsule endoscopy and intermittent bleeding of the lesion, single-balloon enteroscopy was performed when the patient presented with melena again. Enteroscopy showed a submucosal protruding lesion (approximately $0.5 \times 0.5 \mathrm{~cm}$ ) in the middle section of the jejunum that was streaming blood and had white thrombus attached to its surface. A titanium clip was therefore applied to occlude the lesion with the aim of stopping the bleeding temporarily and marking the surgical site ( $\bullet$ Fig. 1 ; - Video 1).

A preoperative abdominal computed tomography (CT) scan clearly demonstrated the lesion site marked by the titanium clip

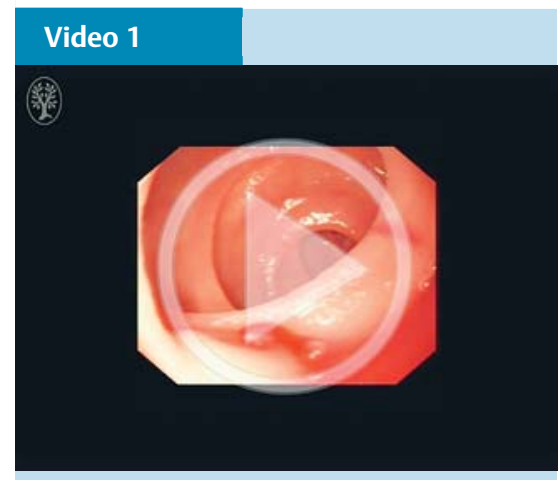

Single-balloon enteroscopy was performed to observe intravascular papillary endothelial hyperplasia real-time in vivo. A titanium clip was applied to occlude the lesion with the aim of stopping the bleeding temporarily and marking the surgical site.

( $\bullet$ Fig.2). Laparoscopic partial enterectomy was performed to completely resect the lesion ( $\mathrm{Fig.3}$ ). Postoperative histopathological examination revealed intravascular papillary endothelial hyperplasia (IPEH) ( Fig.4). The patient was doing well at follow-up 6 months later.

IPEH is a benign exuberant proliferation of endothelial cells that is associated with organizing thrombus [1] and is rare in the GI tract. Here, we performed singleballoon enteroscopy and observed IPEH real-time in vivo for the first time. We found the endoscopic features of IPEH resembled an intestinal stromal tumor or hemangioma. As IPEH is a benign process, complete surgical excision, if possible, is the first-choice to cure the disease [2]. In conclusion, IPEH is rare in the GI tract. We should remain suspicious of IPEH and make the differential diagnosis from other tumors to avoid misdiagnosis or the giving of unnecessary adjuvant therapy.

Endoscopy_UCTN_Code_CCL_1AC_2AB

Competing interests: None 


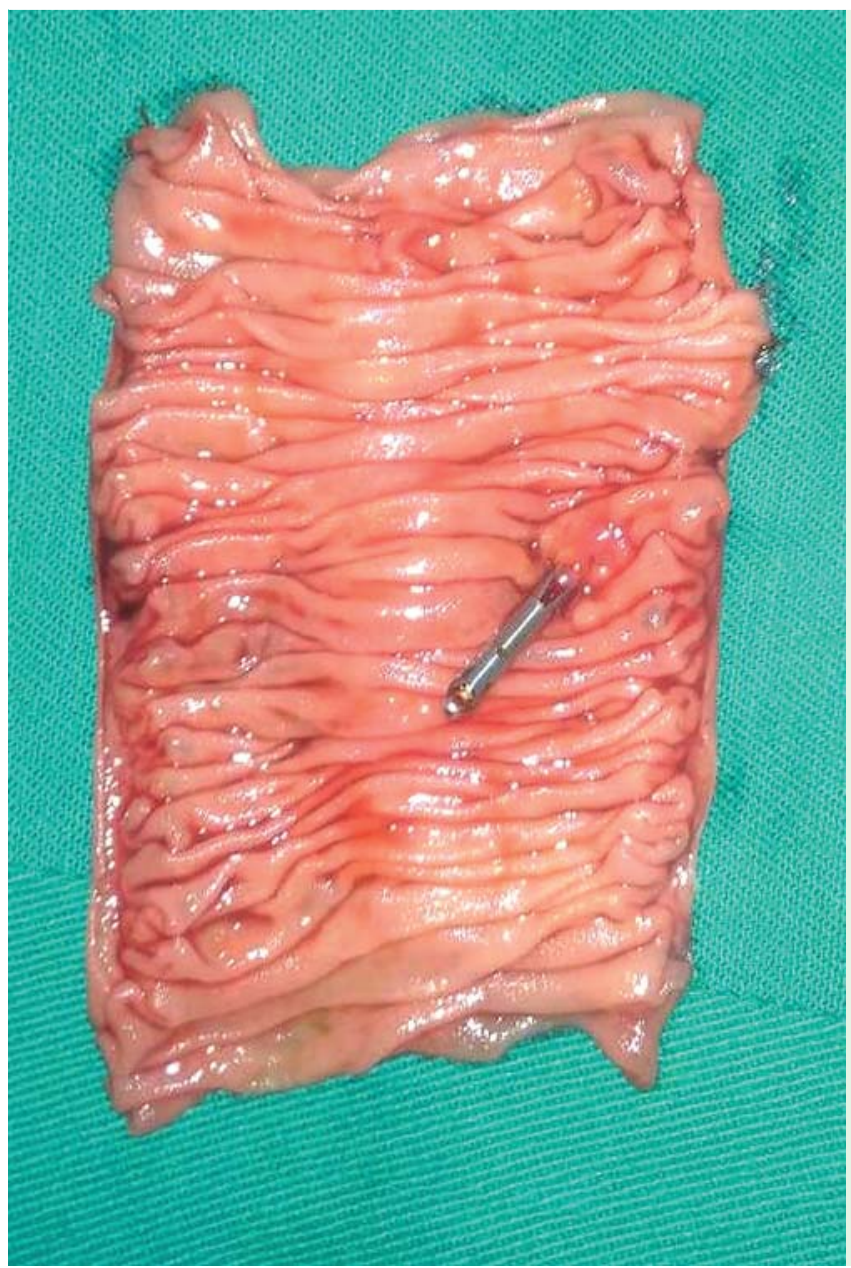

Fig. 3 Macroscopic appearance of the resected specimen showing the lesion within the jejunum.
Mingming Zhang*, Yanbo Yu*, Xiuli Zuo, Wenwen Zheng, Yanqing Li

Department of Gastroenterology, Laboratory of Translational Gastroenterology, Shandong University, Qilu Hospital, Jinan, China

\section{Acknowledgments}

$\nabla$

This study was funded by National Natural Science Foundation of China (grant numbers 81330012 and 81300284 ).

* Mingming Zhang and Yanbo Yu contributed
equally to this work. 

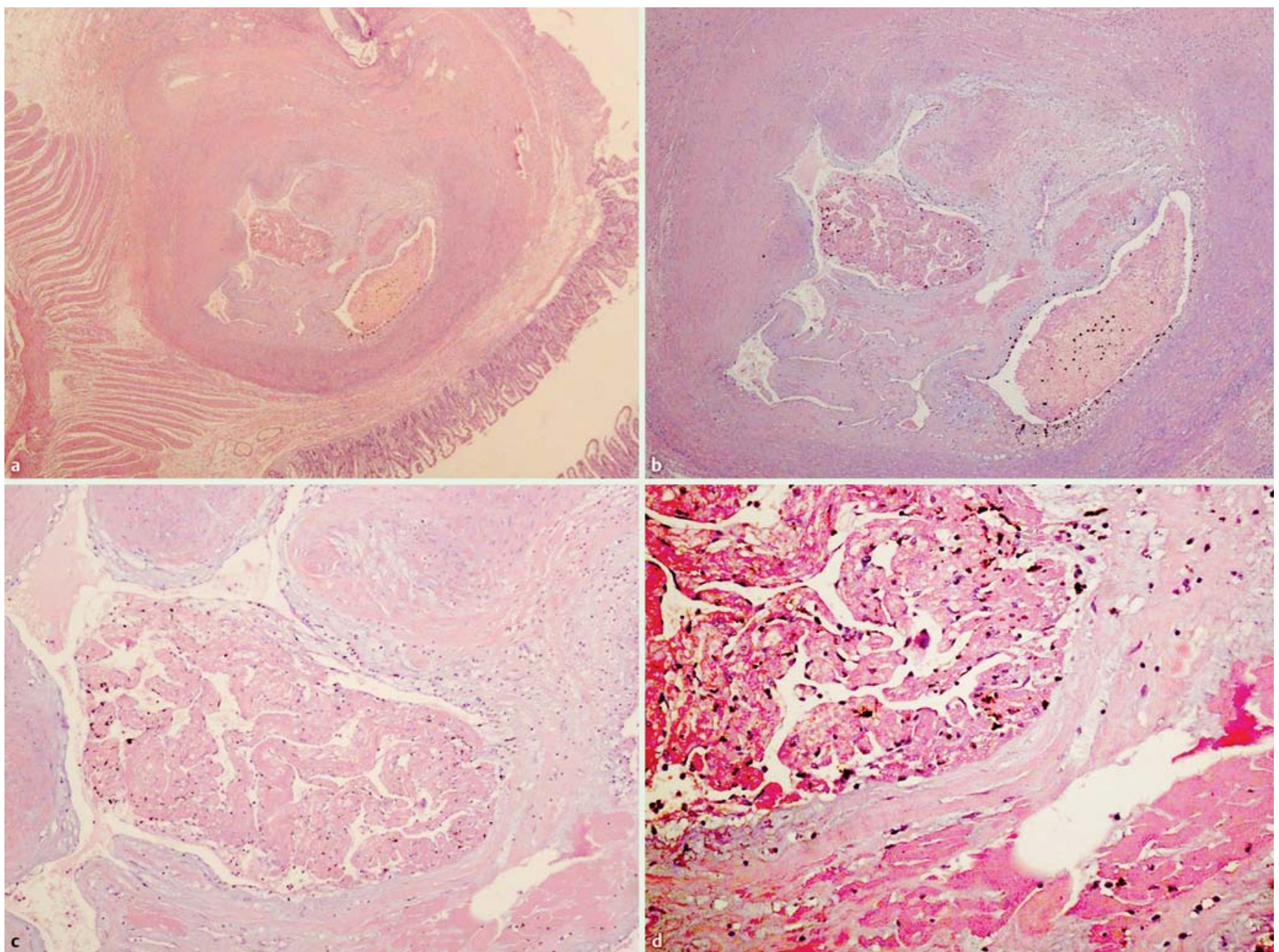

Fig.4 Histological appearance of the hematoxylin and eosin (H\&E)-stained specimen showing an exuberant endothelial proliferation with a papillary architecture attached to the wall of a dilated vessel. The organized thrombus was entrapped by the papillae, which were covered by a single layer of flat or slightly plump endothelial cells. Original magnification: $\mathbf{a} \times 20 ; \mathbf{b} \times 40 ; \mathbf{c} \times 100 ; \mathbf{d} \times 200$.

\section{References}

1 Clearkin KP, Enzinger FM. Intravascular papillary endothelial hyperplasia. Arch Pathol Lab Med 1976; 100: 441 - 444

2 Sim SY, Lim YC, Won KS et al. Thirteen-year follow-up of parasellar intravascular papillary endothelial hyperplasia successfully treated by surgical excision: case report. J Neurosurg Pediatr 2015; 15: 384 - 391

\section{Bibliography}

Dol http://dx.doi.org/

10.1055/s-0041-111029

Endoscopy 2016; 48: E30-E32

(c) Georg Thieme Verlag KG

Stuttgart · New York

ISSN 0013-726X

\author{
Corresponding author \\ Yanqing Li, MD, PhD \\ Department of Gastroenterology \\ Laboratory of Translational Gastroenterology \\ Shandong University, Qilu Hospital \\ 107 Wenhuaxi Road \\ linan 250012 \\ China \\ Fax: +86-531-82166090 \\ liyanqing@sdu.edu.cn
}

